\title{
IDENTIFICAÇÃO DE CONFLITO DE USO DA TERRA EM ÁREAS DE PRESERVAÇÃO PERMANENTE NO ENTORNO DO PARQUE NACIONAL DO CAPARAÓ, ESTADO DE MINAS GERAIS ${ }^{1}$
}

Fernando Soares de Oliveira², Vicente Paulo Soares ${ }^{4}$, José Eduardo Macedo Pezzopane ${ }^{3}$, José Marinaldo Gleriani ${ }^{4}$, Gumercindo Souza Lima ${ }^{4}$, Elias Silva ${ }^{4}$, Carlos Antonio Alvares Soares Ribeiro ${ }^{4}$ e Ângelo Marcos Santos Oliveira ${ }^{2}$

\begin{abstract}
RESUMO - Este estudo teve como objetivos elaborar um mapa de uso da terra com base nas imagens do satélite IKONOS II, delimitar de maneira automática as áreas de preservação permanente e identificar a ocorrência de conflitos de usos, tendo como referência legal o Código florestal e a Resolução n. ${ }^{\circ} 303$ do CONAMA. A pesquisa foi desenvolvida na entorno do Parque Nacional do Caparaó, pertencente aos municípios de Alto Jequitibá, Alto Caparaó, Caparaó e Espera Feliz, todos situados no estado de Minas Gerais. Utilizando os recursos disponíveis no geoprocessamento, foi possível mapear 8 classes de uso da terra e delimitar as áreas de preservação permanente situadas em áreas com altitudes superior a 1.800 metros $(8,42 \mathrm{ha})$, no terço superior dos morros (18,67 ha); encostas com declividade superior a 45 graus (92,96 ha); nascentes e suas respectivas áreas de contribuição (1.989,44 ha); margens dos cursos d’água com largura inferior a 10 metros $(3.957,19$ ha); e no terço superior das sub-bacias $(6.031,54 \mathrm{ha})$, perfazendo um total de $12.098,22$ ha $(48,06 \%)$ da área total da bacia. A área de uso indevido correspondeu a 8.922,91 ha (73,75\%), sendo as classes cafezal $(5.183,43$ ha) e pastagem (3.650,74 ha) as principais ocorrências nessas áreas. Apenas 2.160,69 ha (18,40\%) das áreas de preservação permanente estão protegidas por vegetação nativa.
\end{abstract}

Palavras-chaves: área de preservação permanente; geoprocessamento; uso da terra.

\section{IDENTIFICATION OF LAND USE CONFLICTS IN PERMANENT PRESERVATION ÁREAS IN THE SURROUNDINGS OF THE CAPARAÓ NATIONAL PARK, MINAS GERAIS STATE, BRAZIL}

\begin{abstract}
The objective of this work was to prepare a map of land use based on the IKONOS II sattelite images, to automatically determine the permanent preservation areas and to identify the occurrence of use conflicts, using as legal reference the Forest Code and the $n^{\circ} 303$ Resolution of the CONAMA. The research was developed around the Caparaó National Park, in lands of the municipalities of Alto Jequitibá, Alto Caparaó, Caparaó and Espera Feliz, all of them located in the State of Minas Gerais. Using the resources available in the geographic processing, it was possible to map 8 classes of land use and to delimitate the permanent preservation areas located in regions above 1,800 meters of altitude ( $8.42 \mathrm{ha})$, the third upper part the hills (18.67 ha); an hillsides with slopes above 45 degrees (92.96 ha); water course margins with width below 10 meters (3,957.19 ha); and the upper third part the sub basins totalizing 12,098.22 ha (48.06\%) of the basin total area. The area of improper use corresponds to 8,922.91 ha (45.49\%), being the classes coffee crop $(5,183.43 \mathrm{ha})$ and clear pasture $(3,650.74 \mathrm{ha})$ the main occurrences in these areas. Only 2,160.69 ha $(18.40 \%)$ of the permanent preservation areas are protected by natural vegetation.
\end{abstract}

Keywords: permanent preservation area, geoprocessing, land use.

\footnotetext{
${ }^{1}$ Recebido em 14.02.2007 e aceito para publicação em 22.08.2008.

${ }^{2}$ Programa dePós-Graduaçãoem CiênciaFlorestal da UniversidadeFederal de Viçosa(UFV). E-mail:<fernandosoaresdeoliveira@yahoo.com.br>.

${ }_{3}^{3}$ Departamento de Engenharia Rural da Universidade Federal do Espírito Santo-UFES. E-mail: <jemp@ cca.ufes.br>.

${ }^{4}$ Departamento de Emgenharia Florestal da Universidade Federal de Viçosa (UFV). E-mail:<vicente@ufv.br>.
} 


\section{INTRODUÇÃO}

A expansão antrópica, aliada ao uso indevido do solo, é um dos grandes responsáveis pelas pressões sobre os recursos naturais. Uma das causas dessa expansão é a fragmentação florestal, a qual tem gerado conseqüências negativas nos diferentes compartimentos ambientais (VIANA et al., 1997). A retirada da vegetação nativa tem alterado, entre outros fatores, o balanço da radiação, afetando o microclima (SAUNDERS, 1991); promovido mudanças nos níveis de umidade do solo (KAPOS, 1989); e aumentado o fluxo de água na superfície, facilitando o assoreamento dos mananciais e depreciando a qualidade da água (SILVA, 1994).

Uma das formas de preservar ecossistemas foi a implantação de Unidades de Conservação (UC) como parques nacionais, reservas ecológicas, reservas biológicas e outras. Para minimizar o impacto negativo das atividades humanas em volta dessas unidades, foram estabelecidas zonas de amortecimento nessas áreas (ORLANDO, 1997).

As Áreas de Preservação Permanentes (APPs) previstas no Código Florestal têm a função de proteger o meio ambiente e assegurar-lhe a perpetuidade e o bem-estar das populações humanas. Essas funções são: preservação da paisagem, proteção dos recursos hídricos, proteção do fluxo gênico da fauna e flora e dissipador de energia erosiva (BRASIL, 1965).

Os Sistemas de Informações Geográficas (SIGs) atuais dispõem de diversos recursos para uma modelagem numérica precisa e detalhada do relevo. Esses modelos podem ser utilizados na proposição de metodologias para delimitação automática de APPs, com base nos critérios estabelecidos pela Resolução n. ${ }^{\circ}$ 303, do CONAMA, de 20 de março de 2002. Os produtos derivados a partir desses procedimentos têm substituído, com vantagens, os métodos manuais tradicionalmente utilizados (RIBEIRO et al., 2005), permitido a obtenção de resultados menos subjetivos, em menor tempo e replicáveis (TRIBE, 1992), e apresentado níveis de exatidão comparáveis com os obtidos por métodos manuais (EASH, 1994).

O uso integrado dos Sistemas de Informações Geográficas (SIGs) e Sensoriamento Remoto, sobretudo as imagens de satélite de alta resolução espacial, tendo como referência os aspectos técnicos e legais, pode permitir ao poder público verificar a exeqüibilidade dos projetos de desenvolvimento locais com base na legislação ambiental e na ocorrência do uso inadequado da terra.

R. Árvore, Viçosa-MG, v.32, n.5, p.899-908, 2008
Este estudo teve como objetivo delimitar, de maneira automática, as áreas de preservação permanentes com base nos critérios estabelecidos na Resolução n. ${ }^{\circ}$ 303, do CONAMA, e no Código Florestal Brasileiro, bem como identificar a ocorrência de conflitos de usos da terra no entorno do Parque Nacional do Caparaó, pertencente aos Municípios de Alto Jequitibá, Alto Caparaó, Caparaó e Espera Feliz, todos situados no Estado de Minas Gerais.

\section{MATERIAL E MÉTODOS}

\subsection{Aspectos físicos da área}

A área de estudo está localizada entre as latitudes $20^{\circ} 22^{\prime}$ e $20^{\circ} 37^{\prime}$ sul e longitudes $41^{\circ} 48^{\prime}$ e $41^{\circ} 57^{\prime}$ oeste de Greenwich, estendendo-se por $25.174,84$ ha. Situase na região da Zona da Mata do Estado de Minas Gerais, abrangendo parte dos Municípios de Alto Jequitibá, Alto Caparaó e Caparaó, pertencentes à microrregião de Manhuaçu; e Espera Feliz, pertencente à microrregião de Muriaé. Corresponde a uma faixa de $10 \mathrm{~km}$ de distância da parte mineira do Parque Nacional do Caparaó (Figura 1), de acordo com a Resolução $n^{\circ}$ 13/90, do CONAMA, que determinou essa distância de faixa em torno das Unidades de Conservação.

Segundo a classificação de Köppen, o clima da região é do tipo $\mathrm{Cwb}$, caracterizado pelo inverno seco e verão chuvoso. De maneira geral, a topografia da região possui relevo bastante acidentado, intercalada por reduzidas áreas planas.

\subsection{Material utilizado}

Para a realização deste estudo, utilizaram-se imagens do satélite IKONOS II, com resolução espacial de 4 $\mathrm{m}$, nos intervalos espectrais do visível $(0,52-0,69$ $\mu \mathrm{m})$ e infravermelho próximo $(0,76-0,90 \mu \mathrm{m})$, obtidas em abril de 2004; bases cartográficas planialtimétricas em formato digital na escala de 1:50.000, digitalizadas a partir das folhas SF-24-V-A-I-3 e SF-24-V-A-IV-I (IBGE, 1977), contendo as áreas urbanas, estradas, hidrografia, curvas de nível com eqüidistância de 20 m e os pontos relativos às nascentes. $\mathrm{O}$ tratamento e análise dos dados foram realizados por meio dos softwares IDRISI 14.0, Kilimanjaro (EASTMAN, 2003) e ArcGIS, versão 9.0, módulos ArcMap e ArcInfo Workstation (ESRI, 2004). Foi utilizado também o Sistema de Posicionamento Global Diferencial (DGPS), modelo GTR, para coleta dos Pontos de Controle no Terreno (PCTs) usados na correção geométrica, e o modelo Garmim III Plus, para aferição das informações obtidas da classificação da imagem. 


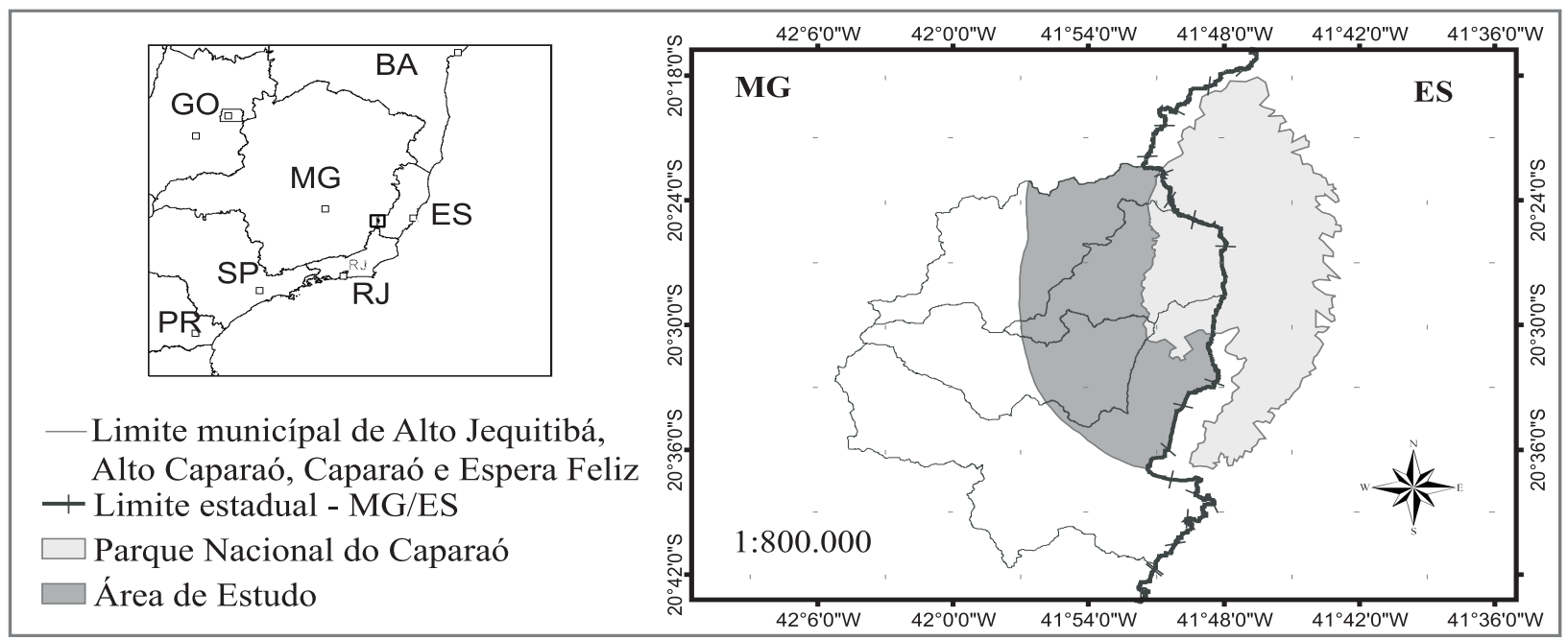

Figura 1 - Entorno do Parque Nacional do Caparaó, inserido nos Municípios de Alto Jequitibá, Alto Caparaó, Caparaó e Espera Feliz, Minas Gerais.

Figure 1 - Surroundings of the Caparaó National Park within the municipalities of Alto Jequitibá, Alto Caparaó, Caparaó, and Espera Feliz, Minas Gerais State, Brazil.

\subsection{Metodologia}

\subsubsection{Classificação visual da imagem}

Inicialmente, foram coletados PCTs para o georreferenciamento da imagem, obtendo-se um RMSe (Root Mean Square Error) de 0,45 pixel. Nessa fase, foi possível inserir a projeção cartográfica Universal Transversa de Mercator (UTM) e o Datum horizontal córrego Alegre (COA). Posteriormente, realizou-se a interpretação visual da imagem IKONOS II, usando as bandas $1(0,45-0,52 \mu \mathrm{m}), 2(0,52-0,60 \mu \mathrm{m})$ e $3(0,63-$ $0,69 \mu \mathrm{m})$, seguida da digitalização das classes de uso da terra. Essa etapa consistiu na distinção dos padrões tonais e das características feições da imagem, como tamanho, forma e textura.

Posteriormente, foram realizadas visitas a campo, objetivando identificar a fidedignidade das categorias de uso da terra geradas na classificação preliminar e também para eliminar possíveis dúvidas. Com a finalidade de verificar a confiabilidade do mapa gerado, foi realizada uma avaliação da exatidão por meio do índice Kappa, conforme a equação 2 .

$$
\hat{\mathrm{K}}=\frac{\mathrm{N} \sum_{i=1}^{r} x_{i i}-\sum_{i=1}^{r} x_{i+} x_{+i}}{\mathrm{~N}^{2}-\sum_{i=1}^{r} x_{i+} x_{+i}}
$$

em que:
$\hat{\mathrm{K}}=$ índice de concordância Kappa; $r$ = número de linhas na matriz; xii = número de observações na linha[i] e coluna[i]; $x i+e x+i=$ totais marginais da linha[i] e coluna[i], respectivamente; e $\mathrm{N}=$ número total de observações.

\subsubsection{Delimitação das Áreas de Preservação Permanentes (APPs) com base na resolução n. ${ }^{\circ}$ 303, do CONAMA}

Foi adotada a metodologia desenvolvida por Ribeiro et al. (2005) para a delimitação automática das áreas de preservação permanente, tomando-se por base o modelo digital de elevação hidrologicamente consistente. Assim, identificaram-se, conforme itens dos art. $2^{\circ} \mathrm{e}$ $3^{\circ}$ da Resolução n. ${ }^{\circ} 303$, do CONAMA, as categorias de APPs situadas em altitudes superiores a $1.800 \mathrm{~m}$ (APP-1), no terço superior dos morros (APP-2), nas encostas com declividade superior a 45 graus (APP3 ), nas nascentes e suas áreas de contribuição (APP4), margens dos cursos d’água (APP-5) e terço superior das sub-bacias (APP-6).

\subsubsection{Desenvolvimento do Modelo Digital Hidrologicamente Consistente (MDHEC)}

Os dados utilizados para geração do MDEHC foram as curvas de nível e a rede hidrográfica, ambas na escala de 1:50.000. Para determinar a menor dimensão no terreno representada no mapa, isto é, a resolução espacial,

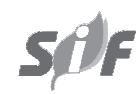

R. Árvore, Viçosa-MG, v.32, n.5, p.899-908, 2008 
multiplicou-se a exatidão cartográfica 0,2 mm (MOURA, 1997) pelo fator de escala, que correspondeu a $10 \mathrm{~m}$.

Determinada a dimensão da célula de saída e de posse dos referidos dados, a geração do MDHEC da bacia hidrográfica do rio Alegre foi realizada utilizandose o algoritmo de interpolação TOPOGRID, disponível no comando Grid tools do módulo ArcInfo Workstation. As operações necessárias para geração do MDHEC, por meio desse algoritmo, exigiram a orientação dos arcos da rede hidrográfica no sentido do escoamento e o ajuste da altimetria à hidrografia.

Em seguida, foram realizadas operações de pósprocessamento, com as finalidades de identificar e eliminar a ocorrência de imperfeições (depressões espúrias) no MDHEC e para criação de uma calha ao longo da rede hidrográfica, objetivando garantir a convergência do escoamento superficial até a foz da hidrografia. De acordo com Tribe (1992), essas imperfeições são muito freqüentes nos MDEs e derivam-se de erros presentes nos dados de entrada ou introduzidos no processo de interpolação. As falsas depressões constituem problema importante na geração de modelos de predição do escoamento, pois interrompem o escoamento superficial. Devem ser removidas, portanto, para se ter um MDE consistente do ponto de vista hidrológico. Para o preenchimento dessas imperfeições, utilizouse o comando FILL, disponível na opção Grid tools do software ArcInfo Workstation.

\subsubsection{Delimitação das Áreas de Preservação Permanentes (APPs)}

Para a delimitação das APPs no terço superior dos morros (APP-2), foram geradas a grade com a altitude das células das bases dos morros e montanhas e a grade com a altitude das células dos topos dos morros e montanhas. Identificaram-se os morros e montanhas invertendo o modelo digital de elevação, sendo os topos identificados como depressões. Para cada depressão, delimitou-se a respectiva bacia de contribuição, cujo contorno representa, então, a base do morro ou montanha.

Adelimitação das APPs ao longo das linhas de cumeada, no terço superior das sub-bacias (APP-6), foi realizada gerandose a grade da bacia de contribuição de cada segmento da rede hidrográfica, em seguida a grade com a altitude das células da hidrografia e finalmente a grade da altitude das células dos divisores de água, selecionando-se as áreas com desníveis maiores que $50 \mathrm{~m}$.

R. Árvore, Viçosa-MG, v.32, n.5, p.899-908, 2008
A delimitação das APPs situadas no entorno das nascentes e suas áreas de contribuição (APP-4) foi feita demarcando-se um raio de $50 \mathrm{~m}$ em torno de cada nascente. Em seguida, delimitou-se a bacia de contribuição. Unindo essas duas áreas, obteve-se a grade final dessa categoria de APP.

As categorias de APPs relativas às áreas com altitudes superiores a $1.800 \mathrm{~m}$ (APP-1), encostas ou elevações com declividade superior a $45^{\circ}$ (APP-3) e às margens dos cursos d'água (APP-5), foram obtidas por meio de funções de seleção por consulta (SELECT) e de geração de margens (BUFFER) disponíveis, respectivamente, no ambiente GRID e ARC do módulo Arc/INFO® workstation.

\subsubsection{Análises de conflito de uso da terra}

Na identificação e análise do conflito de uso nas áreas destinadas à preservação permanente foram utilizados os mapas temáticos de uso e ocupação da terra e das categorias de APPs. Inicialmente, realizouse a sobreposição desses mapas por meio dos procedimentos disponíveis no módulo de análise do ArcMap (Geoprocessing Wizard). Em seguida, as ocorrências de conflito, de acordo com as classes de uso, foram identificadas e devidamente mensuradas, executando-se as funções de busca (Query Build) e de cálculo de área.

\section{RESULTADOS E DISCUSSÕES}

\subsection{Classes de uso da terra}

A imagem do satélite IKONOS, bandas 1, 2 e 3, obtida em abril de 2004 e os levantamentos de campo permitiram identificar e mapear oito classes de uso da terra, destacando-se 529 fragmentos florestais, conforme mostrado na figura 2 .

O mapa representado pela Figura 2 teve a sua acurácia verificada pela matriz de erros, usando-se o índice de concordância Kappa, que considera a proporção de amostras corretamente classificadas correspondentes à razão entre a soma da diagonal principal da matriz de erros (amostras corretamente classificadas) e a soma de todos os elementos dessa matriz (número total da amostra), tendo como referência o número total de classes (COHEN, 1960, citado por ROSENFIELD e FITZPATRICK-LINS, 1986). Assim, o resultado obtido com a utilização do estimador de acerto Kappa (matriz de erros) para a classificação realizada foi de 0,93 , valor considerado excelente $(0,8<\mathrm{K}=1)$ (CONGALTON e GREEN, 1998), indicando que a classificação alcançou resultado satisfatório. 


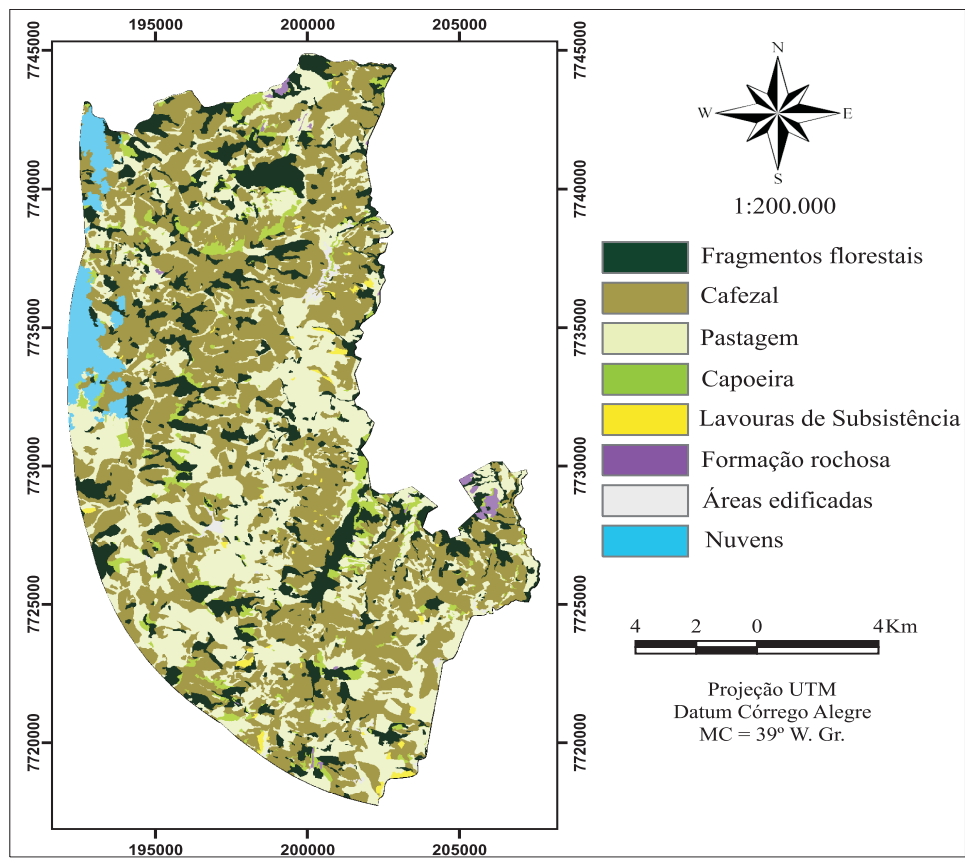

Figura 2 - Mapa de uso e cobertura do solo no entorno do Parque Nacional do Caparaó, Estado de Minas Gerais.

Figure 2-Land use / land cover map on the surroundings of the Caparaó National Park, Minas Gerais State, Brazil.

Com relação às classes mapeadas, a análise do Quadro 1 indica que as classes cafezal e pastagem foram as de maiores ocorrências na área, com 11.440,71 ha e 7.922,00 há, respectivamente. No entanto, exposição rochosa $(96,33$ ha) foi a classe que apresentou a menor contribuição na composição da paisagem.

Considerando as atividades agropecuárias como uma das principais responsáveis pela transformação da paisagem natural, constatou-se que as classes cafezal $(45,45 \%)$, pastagem $(31,47 \%)$ e lavouras de subsistência $(0,54 \%)$ corresponderam a $77,46 \%$ da área. A expressiva participação dessas classes na composição da paisagem demonstra os intensos processos de antropização a que a área tem sido submetida.

A análise das classes de uso da terra distribuidas por municípios (Quadro 2) evidenciou que Alto Jequitibá apresenta a maior taxa de cobertura florestal do entorno (17,32\%), enquanto Alto Caparaó, a menor (12,68\%), talvez pelo fato de a sede desse município localizar-se dentro da região do entorno, causando maior pressão sobre os recursos naturais. A maior área coberta por cafezais $(52,81 \%)$ também se encontrava no Município de Alto Caparaó.

\section{2. Áreas de Preservação Permanente}

A metodologia de delimitação automática das
Àreas de Preservação Permanente (APPs), tendo como referência legal a Resolução n. ${ }^{\circ}$ 303, do CONAMA, possibilitou identificar e quantificar as categorias de APPs situadas em altitudes superiores a 1.800 $\mathrm{m}$, no terço superior dos morros, nas encostas com declividade superior a 45 graus, nas nascentes e respectivas áreas de contribuição, ao longo das margens de cursos d'água e no terço superior das sub-bacias, conforme mostrado na Figura 3.

Quadro 1 - Classes de uso da terra mapeadas na imagem do satélite IKONOS no entorno do Parque Nacional do Caparaó, Minas Gerais

Table 1 - Land use classes based on the IKONOS II sattelite image of the surroundings of the Caparaó National Park, Minas Gerais State, Brazil

\begin{tabular}{llcc}
\hline \multirow{2}{*}{ N. } & Classe de uso e ocupação & \multicolumn{2}{c}{ Área } \\
\cline { 3 - 4 } & & $($ ha $)$ & $(\%)$ \\
\hline 1 & Fragmentos Florestais & $3.674,53$ & 14,60 \\
2 & Cafezal & $11.440,71$ & 45,45 \\
3 & Pastagem & $7.922,00$ & 31,47 \\
4 & Capoeira & $1.035,33$ & 4,11 \\
5 & Lavouras de Subsistência & 136,25 & 0,54 \\
6 & Formação rochosa & 96,33 & 0,38 \\
7 & Área edificada & 117,77 & 0,47 \\
8 & Nuvens & 751,92 & 2,99 \\
\hline \multicolumn{2}{c}{ Total } & $2.5174,84$ & 100,00 \\
\hline
\end{tabular}


Quadro 2 - Classes de uso da terra mapeadas no entorno do Parque Nacional do Caparaó, distribuídas por município Table 2 - Land use classes on the surroundings of the Caparaó National Park, distributed by municipality, Minas Gerais, Brazil

\begin{tabular}{|c|c|c|c|c|c|c|c|c|}
\hline \multirow[t]{3}{*}{ Classe de uso } & \multicolumn{8}{|c|}{ Região do Entorno } \\
\hline & \multicolumn{2}{|c|}{ Alto Jequitibá } & \multicolumn{2}{|c|}{ Alto Caparaó } & \multicolumn{2}{|c|}{ Caparaó } & \multicolumn{2}{|c|}{ Espera Feliz } \\
\hline & ha & $\%$ & ha & $\%$ & ha & $\%$ & ha & $\%$ \\
\hline Fragmentos Florestais & $1.197,68$ & 17,32 & 735,06 & 12,68 & 850,34 & 13,76 & 891,45 & 14,20 \\
\hline Cafezal & $2.934,45$ & 42,44 & $3.062,24$ & 52,81 & $2.562,22$ & 41,45 & $2.881,80$ & 45,89 \\
\hline Pastagem & $1.616,70$ & 23,38 & $1.772,21$ & 30,56 & $2.465,05$ & 39,88 & $2.068,04$ & 32,93 \\
\hline Capoeira & 383,47 & 5,55 & 127,75 & 2,20 & 242,41 & 3,92 & 281,70 & 4,49 \\
\hline Lavoura de Subsistência & 3,32 & 0,05 & 43,30 & 0,75 & 33,41 & 0,54 & 56,22 & 0,90 \\
\hline Formação rochosa & 27,55 & 0,40 & 0,89 & 0,02 & 0,30 & 0,00 & 67,59 & 1,08 \\
\hline Área Edificada & 0,00 & 0,00 & 57,26 & 0,99 & 27,59 & 0,45 & 32,92 & 0,52 \\
\hline \multirow[t]{2}{*}{ Nuvens } & 751,92 & 10,87 & 0,00 & 0,00 & 0,00 & 0,00 & 0,00 & 0,00 \\
\hline & $6.915,09$ & & $5.798,71$ & & $6.181,32$ & & $6.279,72$ & \\
\hline
\end{tabular}

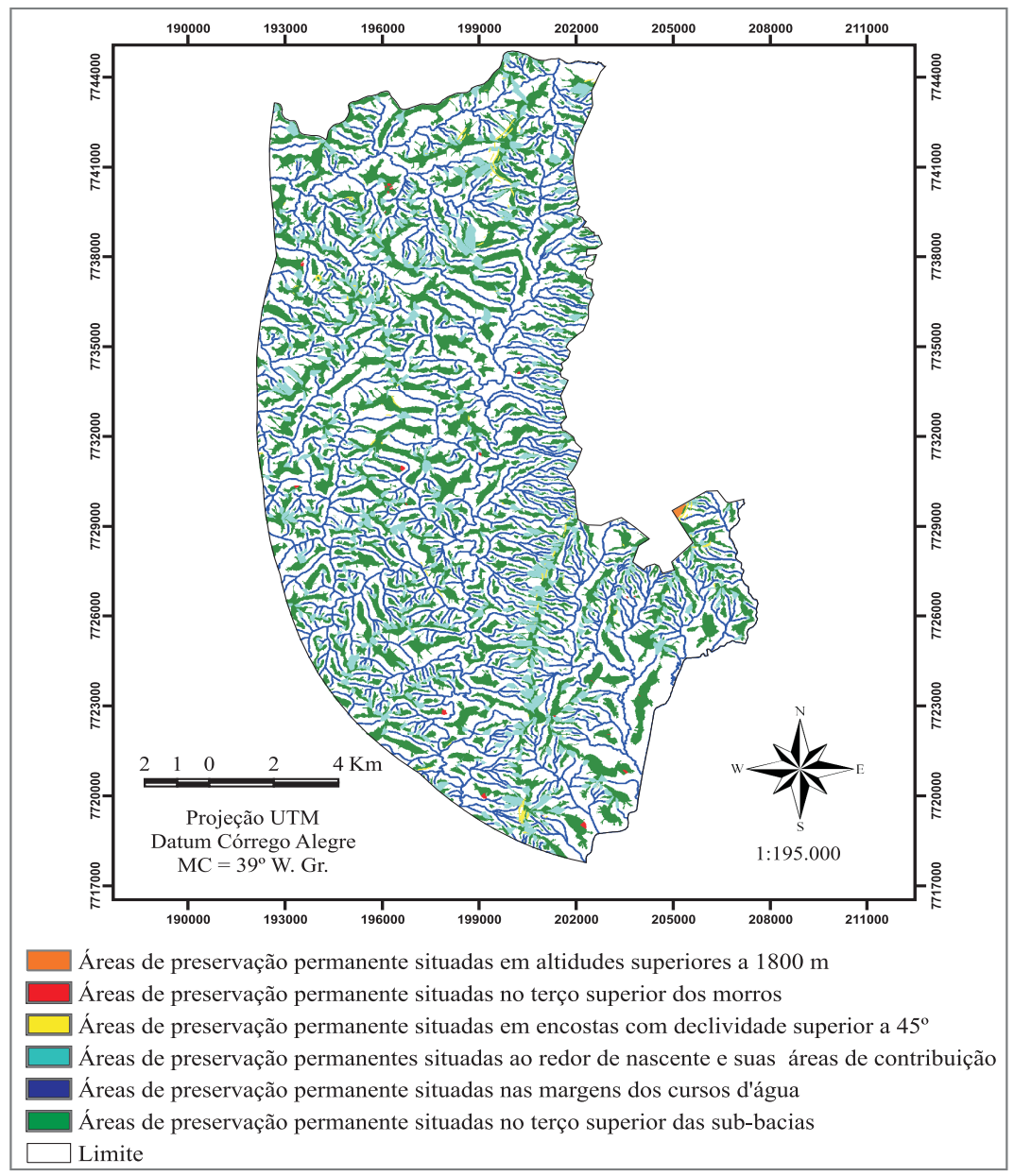

Figura 3 - Categorias de áreas de preservação permanentes mapeadas no entorno do Parque Nacional do Caparaó, Estado de Minas Gerais.

Figure 3 - Categories of Permanent Preservation Areas mapped on the surroundings of the Caparaó National Park, Minas Gerais State, Brazil.

R. Árvore, Viçosa-MG, v.32, n.5, p.899-908, 2008 
A análise do Quadro 3 indicou que a menor e maior participação entre as categorias de APPs corresponderam às APP-1 e APP-6, com 8,42 ha $(0,07 \%)$ e 6.031,54 ha (49,85\%), respectivamente. Também contribuíram com grande porcentagem de APPs as categorias margens dos cursos d'água $(32,71 \%)$ e nascentes e suas áreas de contribuição $(16,44 \%)$. Notou-se, ainda, que as APPs ocupavam uma área de 12.098,22 ha, de um total de $25,174,84$ ha da área da bacia, representando 48,06\% de áreas legalmente protegidas.

Em estudo desenvolvido por Nascimento (2005) na bacia do rio Alegre, Município de Alegre, ES, local com característica topográfica semelhante, foram mapeadas 45,95\% da área como áreas de preservação permanente.

A análise do Quadro 4 apontou que, dos 12.098,22 ha ocupados por APPs na região do entorno do Caparaó, a maior área encontrava-se no Município de Alto Jequitibá (3.417,51 ha) seguida pelos Municípios de Caparaó $(3.099,40)$, Espera Feliz $(2.922,71$ ha) e Alto Caparaó (2.658,60 ha). Observa-se ainda, nesse quadro, que a área de preservação permanente situada em altitudes superiores a 1.800 m está situada no Município de Espera Feliz e corresponde apenas a 0,29\% (8,42 ha) das APPs daquele município. Verifica-se também que, em todos os municípios as APPs situadas no terço superior das sub-bacias, são as de maior abrangência, chegando a 52,70\% da área total das APPs no Município de Alto Caparaó. Apesar do relevo acidentado, áreas situadas no terço superior dos morros e encostas com declividade superior a $45^{\circ}$ possuíram pouca abrangência em todos os municípios, chegando ao máximo de 42,64 ha $(1,25 \%)$ no Município de Alto Jequitibá.

\subsection{Conflito de uso da terra}

De maneira geral, as classes de uso da terra mapeadas estão parcialmente situadas nas áreas legalmente protegidas, sobretudo aquelas resultantes de ações antrópicas, Contudo, apenas as classes pertencentes ao sistema antrópico caracterizam o conflito de uso, pois resultam da intervenção humana. Do total de 12.098,22 ha relativos às APPs, 8.922 .91 ha $(73,75 \%)$ estavam sendo afetados por uso indevido, 661,54 ha $(5,47 \%)$ ocupados pelas classes pertencentes ao sistema fitosionômico natural e 2.160,69 ha $(17,86 \%)$ cobertos por fragmentos florestais nativos. Os 353,08 ha $(2,92 \%)$ restantes encontravam-se cobertos por nuvens, impedindo a análise.

Quadro 3 - Quantificação das áreas de preservação permanentes mapeadas no entorno do Parque Nacional do Caparaó, Estado de Minas Gerais

Table 3 - Quantification of the Permanent Preservation Areas in the surroundings of the Caparaó National Park, Minas Gerais, Brazil

\begin{tabular}{lcc}
\hline Descrição das categorias de APPs & Categorias de APPS & Área \\
\cline { 2 - 3 } & & \multirow{2}{*}{$(\%)$} \\
\hline Altitudes superiores a 1.800 metros & APP-1 & 8,42 \\
Terço superior dos morros & APP-2 & 18,67 \\
Encostas com declividade superior a 45 & APP-3 & 0,07 \\
Nascentes e suas áreas de contribuição & APP-4 & 15 \\
Margens dos cursos d’água & APP-5 & 1989,44 \\
Terço superior das sub-bacias & APP-6 & 3957,19 \\
Total & & 6031,54 \\
\hline
\end{tabular}

Quadro 4 - Quantificação das áreas de preservação permanentes mapeadas no entorno do Parque Nacional do Caparaó, distribuídas por município

Table 4-Quantification of the Permanent Preservation Areas in the surroundings of the Caparaó National Park, distributed by municipality, Minas Gerais, Brazil

\begin{tabular}{|c|c|c|c|c|c|c|c|c|}
\hline \multirow[t]{2}{*}{ Categorias de APPS } & \multicolumn{2}{|c|}{$\begin{array}{c}\text { Alto Jequitibá } \\
\text { Área }\end{array}$} & \multicolumn{2}{|c|}{$\begin{array}{c}\text { Alto Caparaó } \\
\text { Área }\end{array}$} & \multicolumn{2}{|c|}{$\begin{array}{c}\text { Caparaó } \\
\text { Área }\end{array}$} & \multicolumn{2}{|c|}{$\begin{array}{c}\text { Espera Feliz } \\
\text { Área } \\
\end{array}$} \\
\hline & (ha) & $\%$ & (ha) & $\%$ & (ha) & $\%$ & (ha) & $\%$ \\
\hline APP-1 & - & - & - & - & - & - & 8,42 & 0,29 \\
\hline APP-2 & 3,74 & 0,11 & 2,68 & 0,10 & 4,38 & 0,14 & 7,87 & 0,27 \\
\hline APP-3 & 42,64 & 1,25 & 7,68 & 0,29 & 13,85 & 0,45 & 28,79 & 0,99 \\
\hline APP-4 & 658,55 & 19,27 & 326,02 & 12,26 & 534,72 & 17,3 & 470,15 & 16,09 \\
\hline APP-5 & 907,82 & 26,56 & 921,18 & 34,65 & 1096,98 & 35,4 & 1031,21 & 35,28 \\
\hline \multirow[t]{2}{*}{ APP-6 } & 1804,76 & 52,81 & 1401,04 & 52,70 & 1449,47 & 46,8 & 1376,27 & 47,09 \\
\hline & 3417,51 & & 2658,6 & & 3099,4 & & 2922,71 & \\
\hline
\end{tabular}


Em estudo desenvolvido por Soares et al. (2002) em uma microbacia localizada no Município de Viçosa, MG, a analise do uso do solo indicou que $24,56 \%$ da área encontrava-se em conflito de uso.

A análise do Quadro 5 indicou que as classes de cafezal e pastagem ocuparam as maiores áreas de APPs, com $5.183,43$ ha $(42,84 \%)$ e $3.650,74$ ha $(30,18 \%)$, respectivamente. As áreas de APPs situadas nas margens de cursos d'água (APP-5) e no terço superior das subbacias (APP-6), com 3.162,80 ha e 4.353,30 ha, respectivamente, foram as categorias mais afetadas por essas duas classes de uso da terra. Entretanto, observouse que as áreas ocupadas pelas classes caracterizadas como sistemas fitofisionômicos naturais ocorreramemapenas $23,33 \%$ das categorias de APPs, sendo 2.160,69 ha cobertos por fragmentos florestais. Com relação aos fragmentos florestais, vale ressaltar que estes representam áreas efetivamente preservadas com cobertura vegetal nativa. Ainda no Quadro 5, verificou-se que as classes Áreas Edificadas e Lavouras de Subsistência, com 31,07 ha e 57,67 ha, respectivamente, ocupavam as menores porções entre as categorias de APPs mapeadas.

Quadro 5 - Quantificação da ocorrência de conflito de uso da terra nas categorias de áreas de preservação permanentes delimitadas no entorno do Parque Nacional do Caparaó, Estado de Minas Gerais

Table 5 - Quantification of the occurrence of land use conflict in the Permante Preservation Areas categories in the surroundings of the Caparaó National Park, Minas Gerais, Brazil

\begin{tabular}{|c|c|c|c|c|c|c|c|c|c|}
\hline \multirow{2}{*}{\multicolumn{2}{|c|}{ Classes de uso da terra }} & \multirow[b]{2}{*}{ APP-1 } & \multicolumn{5}{|c|}{ Categorias de APPs } & \multicolumn{2}{|c|}{ Total (Área) } \\
\hline & & & APP-2 & \multirow{2}{*}{$\begin{array}{l}\mathrm{APP}-3 \\
1409\end{array}$} & \multirow{2}{*}{$\begin{array}{l}\text { APP-4 } \\
801,65\end{array}$} & \multirow{2}{*}{$\frac{\text { APP-5 }}{1531.04}$} & \multirow{2}{*}{$\frac{\text { APP-6 }}{2830,28}$} & \multirow{2}{*}{$\begin{array}{c}\text { (ha) } \\
5183,43\end{array}$} & \multirow{2}{*}{$\frac{(\%)}{42,84}$} \\
\hline$\overline{\text { Sistema }}$ & Cafezal & - & 6,37 & & & & & & \\
\hline \multirow[t]{3}{*}{ Antrópico } & Pastagem & - & 5,18 & 25,71 & 465,07 & 1631,76 & 1523,02 & 3650,74 & 30,18 \\
\hline & $\begin{array}{l}\text { Lavoura de } \\
\text { Subsistência }\end{array}$ & - & 2,20 & , & 5,91 & 26,35 & 23,21 & 57,67 & 0,48 \\
\hline & Àrea Edificada & - & - & 0,03 & - & 30,24 & 0,80 & 31,07 & 0,26 \\
\hline $\begin{array}{l}\text { Sistema } \\
\text { Fito- }\end{array}$ & $\begin{array}{l}\text { Fragmentos } \\
\text { Florestais }\end{array}$ & 0,36 & 3,72 & 28,64 & 497,81 & 496,39 & 1133,77 & 2160,69 & 17,86 \\
\hline \multirow{2}{*}{ fisionômico } & Capoeira & _ & 1,20 & 15,59 & 145,26 & 138,82 & 294,49 & 595,36 & 4.92 \\
\hline & $\begin{array}{l}\text { Formação } \\
\text { Rochosa }\end{array}$ & 8,06 & , & 7,30 & 11,46 & 7,91 & 31,45 & 66,18 & 0,55 \\
\hline \multicolumn{2}{|c|}{ Nuvens } & - & - & 1,60 & 62,28 & 94,68 & 194,52 & 353,08 & 2,92 \\
\hline \multicolumn{2}{|c|}{ Total } & 8,42 & 18,67 & 92,96 & 1989,44 & 3957,19 & 6031,54 & 12098,22 & \\
\hline
\end{tabular}

Quadro 6 - Quantificação do conflito de uso da terra entre os municípios do entorno do Parque Nacional do Caparaó, Estado de Minas Gerais

Table 6 - Quantification of the land use conflict among the municipalities on the surroundings of the Caparaó National Park, Minas Gerais, Brazil

\begin{tabular}{|c|c|c|c|c|c|c|}
\hline \multirow[t]{3}{*}{ Município } & \multirow[t]{3}{*}{ Classe de uso do solo } & \multicolumn{5}{|c|}{ Ocorrência } \\
\hline & & \multicolumn{2}{|c|}{ Uso devido } & \multicolumn{2}{|c|}{ uso indevido } & \multirow{2}{*}{$\begin{array}{c}\text { Total } \\
\text { (ha) }\end{array}$} \\
\hline & & (ha) & $(\%)$ & (ha) & $(\%)$ & \\
\hline \multirow[t]{3}{*}{ Alto Jequitibá } & Cafezal & 1637 & 55,79 & 1297,45 & 44,21 & 2934,45 \\
\hline & Pastagem & 834,7 & 51,63 & 782 & 48,37 & 1616,70 \\
\hline & Lavoura de Subsistência & 2,15 & 64,76 & 1,17 & 35,24 & 3,32 \\
\hline \multirow[t]{4}{*}{ Alto Caparaó } & Cafezal & 1742,11 & 56,89 & 1320,13 & 43,11 & 3062,24 \\
\hline & Pastagem & 975,59 & 55,05 & 796,62 & 44,95 & 1772,21 \\
\hline & Lavoura de Subsistência & 26,61 & 61,45 & 16,69 & 38,55 & 43,30 \\
\hline & Área edificada & 45,88 & 80,13 & 11,38 & 19,87 & 57,26 \\
\hline \multirow[t]{4}{*}{ Caparaó } & Cafezal & 1351,14 & 52,73 & 1211,08 & 47,27 & 2562,22 \\
\hline & Pastagem & 1252,22 & 50,80 & 1212,83 & 49,20 & 2465,05 \\
\hline & Lavoura de Subsistência & 15,48 & 46,33 & 17,93 & 53,67 & 33,41 \\
\hline & Área edificada & 14,51 & 52,59 & 13,08 & 47,41 & 27,59 \\
\hline \multirow[t]{4}{*}{ Espera Feliz } & Cafezal & 1527,03 & 52,99 & 1354,77 & 47,01 & 2881,80 \\
\hline & Pastagem & 1208,75 & 58,45 & 859,29 & 41,55 & 2068,04 \\
\hline & Lavoura de Subsistência & 34,34 & 61,08 & 21,88 & 38,92 & 56,22 \\
\hline & Área edificada & 26,31 & 79,92 & 6,61 & 20,08 & 32,92 \\
\hline
\end{tabular}

R. Árvore, Viçosa-MG, v.32, n.5, p.899-908, 2008 
O Quadro 6 mostra o conflito de uso no entorno entre os municípios. No Município de Alto Jequitibá, a classe cafezal possui a maior área em conflito de uso com 1.297,45 ha $(44,21 \%)$ dos 2.934,45 ha. EmAlto Caparaó, a classe pastagem é a que possuía maior área relativamente emáreailegais, com 44,95\% (796,62 ha). Os 17,93 ha (53,67\%) dos 33,41 ha de Lavoura de Subsistência do entorno no Município de Caparaó encontrava-se em áreas de preservação permanente, ou seja, áreas ilegais. Em espera Feliz, 1.527,03 (52,99\%) dos 2.881,80 ha de cafezal encontravam-se legalmente implantadas.

\section{CONCLUSÕES}

A utilização de imagens de alta resolução espacial (IKONOS) permitiu a elaboração do mapeamento, valendo-se da classificação visual e verificações de campo, de oito classes de uso da terra: Fragmentos Florestais, Cafezal, Pastagem, Capoeira, Lavoura de Subsistência, Formação Rochosa, Área Edificadas e Área Coberta por Nuvens.

As categorias de áreas de preservação permanentes situadas em altitudes superiores a $1.800 \mathrm{~m}$, nas margens dos cursos d'água, encostas com declividade superior a 45 graus, áreas de contribuição das nascentes, terço superior do morro e terço superior das sub-bacias ocupavam 12.098,22 ha (48,06\%) da área total do entorno, que era de 25.174,84 ha. Entre essas, a maior participação correspondeu às APPs situadas no terço superior das sub-bacias, com $6.031,54$ ha $(49,85 \%)$, e a menor nas áreas relacionadas às altitudes superiores a $1.800 \mathrm{~m}$, com apenas 8,42 ha $(0,07 \%)$. A região do entorno situada no Município de Caparaó apresentava 50,14\% da área situada em área de preservação permanente.

Em se tratando do conflito de uso da terra, as classes Cafezal (5.183,43 ha) e Pastagem (3.650,74 ha) foram as de maiores ocorrências, ocupando, respectivamente, 45,31 e 46,08\% das áreas legalmente protegidas pela legislação ambiental. Em contrapartida, a classe de Área Edificada $(117,77)$ apresentou a menor ocorrência de uso indevido, com $26,38 \%$.

\section{REFERÊNCIAS}

BRASIL. Leis e decreto, etc Presidência da República. Lei Federal n. ${ }^{\circ} 4.771$, Institui o Novo Código Florestal Brasileiro de 15 de setembro de 1965. Diário oficial [da] República Federativa do Brasil, Casa Civil, Brasília.
CONGALTON, R. G.; GREEN, K. Assessing the accuracy of remotely sensed data: Principles and practices. New York: Lewis Publishers, 1998. $137 \mathrm{p}$.

EASTMAN, J. R. Guide to Gis and image processing: IDRISI KILIMANJARO. Wocester: Clark University, 2003.

\section{ENVIRONMENTAL SYSTEMS RESEARCH INSTITUTE - ESRI. ArcGIS Professional GIS for the desktop, versão 9.0. 2004.}

EASH, D. A. A. Geographic information system procedure to quantify drainage-basin characteristic. Water Resources Bulletin, v.30, p.1-8, 1994.

\section{INSTITUTO BRASILEIRO DE GEOGRAFIA E} ESTATÍSTICA - IBGE, Cartas topográficas: Espera Feliz e Manhumirim. 1977. Escala 1:50.000.

KAPOS, V. Effects of isolation on the water status of forest. Patches in the Brazilian Amazon.

Journal of Tropical Ecology, v.5, n.1, p.173-185, 1989.

MOURA, A. C. M. Globalização e metodologia no uso do geoprocessamento: estudo de casos de diferentes abordagens de análises espaciais, In: CONGRESSO BRASILEIRO DE CARTOGRAFIA, 18., 1997, Rio de Janeiro. Anais... Rio de Janeiro: 1997.

ORLANDO, H. Unidades de conservação e manejo da zona de entorno. In: CONGRESSO BRASILEIRO DE UNIDADES DE CONSERVAÇÃO, 1., 1997, Curitiba. Anais... Curitiba: IAP, UNILIVRE, Rede Nacional Pró-Unidades de Conservação, 1997. 2v.

NASCIMENTO, M. C. et al. Uso do geoprocessamento na identificação de conflito de uso da terra em áreas de preservação permanente na bacia hidrográfica do rio Alegre, Espírito Santo. Ciência Florestal, v.15, n.2, p.207-220, 2005.

RIBEIRO, C. A. A. S. et al. O desafio da delimitação de áreas de preservação permanente. Revista Árvore, v.29, n.2, p.203-212, 2005. 
ROSENFIELD, G. H.; FITZPATRICK-LINS, K. A. coefficient of agreement as a measure of thematic classification accuracy. Photogrammetric Engineering and Remote Sensing, v.52, n.2, p.223-227, 1986.

SAUNDERS, D. A. et al. Biological consequences of ecosystem fragmentation: a review. Conservation Biology, v.5, n.1, p.18-35, 1991.

SILVA, E. Código Florestal Brasileiro: função e áreas de preservação permanente. In. SIMPÓSIO INTERNACIONAL SOBRE ECOSSISTEMAS FLORESTAIS, 4., 1996, Belo Horizonte, MG. Anais... Belo Horizonte: 1996. p.48.
SOARES, V. P. et al. Avaliação das áreas de uso indevido da terra em uma microbacia no município de Viçosa-MG, através de fotografias aéreas e sistema de informação geográfica. Revista Árvore, v.26, n.2, p.243-251, 2002.

TRIBE, A. Automated recognition of valley lines and drainage networks from grid digital elevation models: a review and a new method. Journal of Hidrology, v.139, n.1/4, p.263-293, 1992.

VIANA, V. M. Conservação da biodiversidade de fragmentos florestais em paisagens tropicais intensamente cultivadas. In: ABORDAGENS interdisciplinares para a conservação da biodiversidade e dinâmica do uso da terra. Belo Horizonte: 1985. p.135-154. 